\title{
Performance Analysis of Soft Computing and Image Processing Based Image Segmentation
}

\author{
Nilesh B. Bahadure ${ }^{1}$, Arun Kumar Ray ${ }^{2}$, and H. Pal Thethi ${ }^{3}$
}

\begin{abstract}
Image segmentation is an important class of image analysis in digital image processing and is mainly used in the varieties of applications; some of them are sorting product in the industry, surveillance system, environmental or climate predictions and medical imaging etc. The main objective of the image segmentation is to partition an image into regions. In this paper an attempt is made to find which technique or algorithm is best suited for the image segmentation. The analysis are made on the image segmentation using fuzzy based algorithm, watershed segmentation algorithm and Simulink based design and the performance is judge on the basis of different quality parameters like MSE, PSNR, SSIM and execution speed to generate the result.
\end{abstract}

Keywords - C- Means of clustering, histogram equalization, K Means of clustering, Neuro fuzzy system, Watershed segmentation

\section{INTRODUCTION}

A $\mathrm{N}$ ANFIS system is formed by a Neuro- fuzzy system (NFS) which is a combination of ANN and Fuzzy systems [1]. The entire mechanism is adaptive for which it can track subtle variations in the input patterns. We hereby briefly cover the basic notions related to the system which is appropriately modified for information extraction from the different set of images. A subtractive clustering algorithm is adopted to enhance the performance of the ANFIS model, which has a disadvantage in that the number of control rules increases rapidly as the number of fuzzy variables increases. Clustering especially fuzzy based clustering is an unsupervised learning technique and is the collection of similar type of objects into a single group. There are various types of clustering techniques among which $\mathrm{K}$ - Means Clustering (KMC) or fuzzy C means clustering is the most commonly and popularly used where $\mathrm{K}$ is the number of cluster centres defined by the user.

The main objective of the image segmentation is to partition an image into regions [2]. Different techniques are available for the image segmentation, but the technique which are consider here for the analysis is based on image segmentation using watershed transformation algorithm [3]. The watershed

Nilesh B. Bahadure ${ }^{1}$ is Research Scholar, at School of Electronics, KIIT University, Bhubaneswar, Odissa, India.

Arun Kumar Ray ${ }^{2}$ is currently Dean School of Electronics at KIIT University, Bhubaneswar, Odissa, India.

H. Pal Thethi ${ }^{3}$ is Dean Industry Institute Interface and Professor (ET \& T) at Rungta College of Engineering \& Technology Bhilai, Chhattisgarh, India. transformation is a simplified transformation technique which is mostly preferred for the gray scale image processing to solve the variety of image segmentation problems. Further, the watershed segmentation uses two kind of transformation process namely distance transformation and gradient. The gradient based analysis is mainly used to pre-process a gray scale image prior to using the watershed transform for the image segmentation. The gradient directed image has high pixel values along object edges, and low pixel values everywhere else, so it seems like when the object edges are detected then it gives high pixel value, otherwise low pixel value, and this way pre-processing is done on the gray scale images before the actual segmentation transformation. The major problem associated with the watershed segmentation based transformation is that too many watershed ridge lines will appear in the images and over segmentation. To handle and overcome these difficulties it is need to limit the number of allowable regions by incorporating to bring additional knowledge base in the segmentation procedure. The substituted approach used to overcome the problem of over segmentation is based on the concept of marker. Further, with the help of marker based scheme which lies by top hat and top bottom analysis is also incorporated to reduce the problems of watershed ridge lines and over segmentation

\section{FUZZY C - MEANS CLUSTERING ALGORITHM}

Due to the illumination and the appropriate threshold, the image segmentation of objects whose color composition is not common represents is a difficult task. In this paper we propose the fuzzy C - Means algorithm [1] based techniques for the segmentation of such objects or images. The inspiration behind the use of fuzzy $\mathrm{C}-$ means of clustering is that, clustering algorithms are extensively used to organize and categorize data and also it is well tested for the data compression and model construction. Clustering techniques partitions a data set into several groups such that the similarity within a group is larger than that among groups.

The fuzzy c - means (FCM) algorithms generalizes the hard $\mathrm{C}$ - means or $\mathrm{K}$ - means clustering algorithm in order to allow a point to partially belong to multiple clusters. Due to this the FCM algorithm is used to produces the soft partition, more effectively a constrained soft partition for the given data sets. To perform the soft partition, the objective function $\mathrm{J}_{1}$ of the hard $\mathrm{C}$ - means clustering has been extended by two ways.

(a) The fuzzy membership degrees in clusters were incorporated into the equation as shown in 1. 
(b) Then an additional parameter $\mathrm{m}$ was introduced as a weight exponent in the fuzzy membership.

$$
J(P, V)=\sum_{J=1}^{C} \sum_{X_{i} \in C_{j}}\left|x_{i}-v_{j}\right|^{2}
$$

Where $\mathrm{V}$ denotes vector of cluster and $\mathrm{P}$ denotes the function of partition of the data set $\mathrm{x}$ formed by clusters as $\mathrm{C}_{1}, \mathrm{C}_{2} \ldots \mathrm{C}_{\mathrm{k}}$.

The extended objective function, denoted as $\mathbf{J}_{\mathrm{m}}$ is,

$$
J_{m}(P, V)=\sum_{J=1}^{C} \sum_{X_{i} \in C_{j}}\left(\mu c_{i}\left(x_{k}\right)\right)^{m}\left|x_{k}-v_{i}\right|^{2}
$$

The parameter $\mathrm{m}$ is a weight that determines the degrees to which partial members of a cluster affects the clustering result. It was also depicted that like the hard $\mathrm{C}-$ means of the clustering techniques, FCM also tries to find a good partition by searching for the prototypes $\mathrm{v}_{\mathrm{i}}$ that minimizes the extended objective function $\mathrm{J}_{\mathrm{m}}$, but unlike the hard $\mathrm{C}$ - means of the clustering the FCM also needs to search for the extended membership $\mu c_{\mathrm{i}}$ that minimize $\mathrm{J}_{\mathrm{m}}$.

A constrained fuzzy partition of cluster $C_{1}, C_{2} \ldots C_{k}$ can be a local minimum of extended objective function $\mathrm{J}_{\mathrm{m}}$ only of the following conditions are satisfied.

$$
\begin{array}{r}
\mu c_{i}(x)=\frac{1}{\sum_{j=1}^{k}\left(\frac{\left|x-v_{i}\right|^{2}}{\left|x-v_{j}\right|^{2}}\right)^{\frac{1}{m-1}}} \\
v_{i}=\frac{\sum_{x \in X}\left(\mu c_{i}(x)\right)^{m} x}{\sum_{x \in X}^{n}\left(\mu c_{i}(x)\right)^{m}}
\end{array}
$$

Based on the equation (3) and (4), the fuzzy C - means clustering updates the prototype and the membership function iteratively until a convergence criterion is reached, this iterative or repetitive process is explain in the FCM algorithm. The fuzzy $\mathrm{C}$ - means of clustering for the segmentation of the image into different clusters can be summarized in the following steps.

\section{A. FCM Algorithm}

Step 1: Select the initial class prototype $\left\{\mathrm{v}_{\mathrm{i}}\right\}_{\mathrm{i}=1}^{\mathrm{c}}$

Step 2: Update all membership function $\mu \mathrm{c}_{\mathrm{i}}(\mathrm{x})$

Step 3: Obtain the prototype of the clusters in the form of weighted average constrained values

Step 4: Repeat the steps 2 and 3 till termination and convergence criterion is reached. The computation of the membership is continuing until $\sum_{i=1}^{C}\left|v_{i(\text { new })}-v_{i(\text { (oid) })}\right| \leq \varepsilon$. Where $\mathrm{v}$ is the vector of cluster centers $\varepsilon$ is a small number that can be set by the user.

\section{WATERSHED BASED IMAGE SEGMENTATION}

Watershed based image segmentation [4], sometimes also referred in general term as watershed technique is a strong mathematical morphological tool for the image segmentation. Watershed based segmentation is popular in the areas like biomedical \& medical imaging processing, and computer vision [5]. In geographical term, watershed means the ridge that divides areas drained by different river systems and hence the name of this technique is watershed based segmentation. If an image is viewed as geographical landscape, the watershed lines are determining boundaries which separate image regions. The watershed segmentation transformation computes catchment basins and ridgelines also known as watershed lines, where catchment basins are corresponding to image regions and watershed lines corresponding to the region boundaries [3].

The block diagram for the watershed based segmentation is shown in the Fig. 1. In these techniques when watershed algorithm is applied then it will generate extensive watershed lines for the segmentation, so to reduce the effect of that rigidness, marker technique is applied, this processing operation is called post processing operation of watershed segmentation.

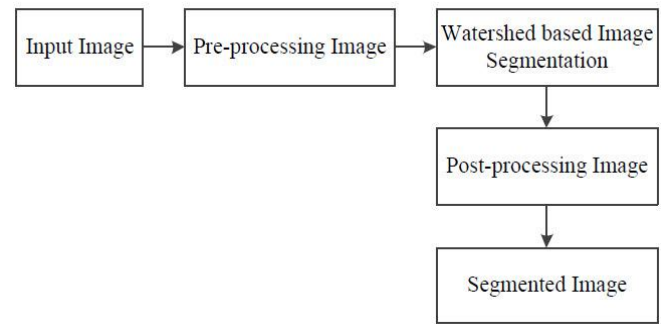

Fig. 1 Block diagram of watershed based segmentation

Watershed based segmentation embodies many of the concepts of three techniques such as threshold based, edge based and region based segmentation [7, 8]. The basic concept of the watershed method used for the image segmentation is to find the watershed lines and then the transformation is done for dividing the image in to the different regions. For example, imagine, holes at each regional minimum, and water is flooded from bottom into these holes with a constant rate. Water level will rise in the topographic surface uniformly. When the rising water in different catchment basins is going to merge with nearby catchment basins, then a dam is built to prevent all merging of the water. Flooding of water will reach at the point when only top of the dams are visible above water line. These continuous dam boundaries are the watershed lines.

\section{IMPLEMENTATION}

For the analysis and to implement the segmentation system it is required to use as data an image of the object to be segment. Each pixel of the image is coded in three components that are represented respectively with the red, green and blue color. The segmentation for the fuzzy based system and an image processing system is implemented using the simulation of Matlab, and the comparison of the performance of the result 
using the two approaches as fuzzy based and image processing based system is also incorporated. For the Simulink based design, the histogram equalization technique is used.

The Simulink design for the image segmentation using histogram equalization is shown in the Fig. 2. The block of MSE calculator is actually Matlab function block from user defined function, in which the Matlab code is to be written by the user according to the requirement and uses of the block.

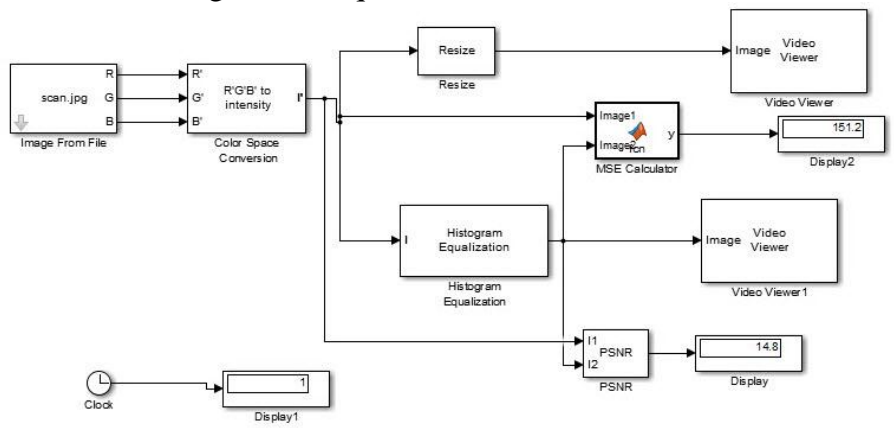

Fig. 2 Simulink based image segmentation

\section{RESULT}

The different techniques of image segmentation is done and verified the result using watershed segmentation and fuzzy $\mathrm{C}$ means algorithms. The result is also obtained using the Simulink design with histogram equalization method. To show the various results from the different techniques the graphical user interface (GUI) is design in the Matlab. All the results are tested on the PC with Intel(R) Core i3 CPU with $2.4 \mathrm{GHz}$ Processor and $6 \mathrm{~GB}$ of DDR RAM, running MATLAB 2014(a) on Windows 8 Professional operating system.

Figure 3, shows the result obtained by comparing execution speed for different segmentation methods. Figure 4, shows the result obtained using the watershed algorithm, figure 5 shows the result obtained using $\mathrm{C}$ - means of clustering algorithm and figure 6 shows the result obtained using Simulink based design. For the watershed based segmentation algorithm, the result for the both i.e. before post - processing and after post processing is shown, similarly in case of $\mathrm{C}$ - means clustering algorithm, the results are shown for cluster size 2 and 3 and result for the image segmentation using Simulink design is shown in the figure 6.

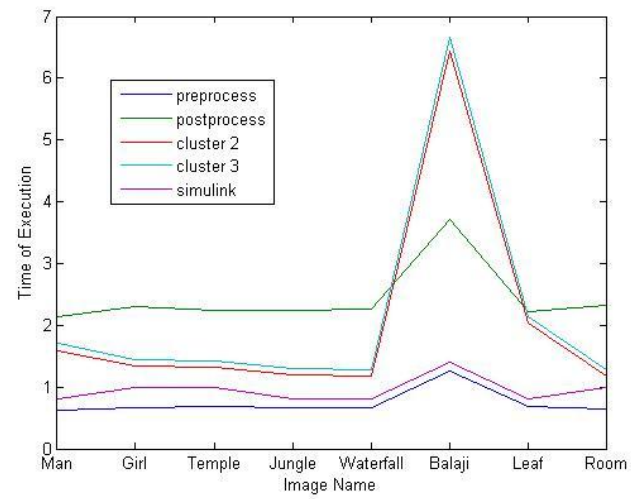

Fig. 3 Speed of execution for the image segmentation

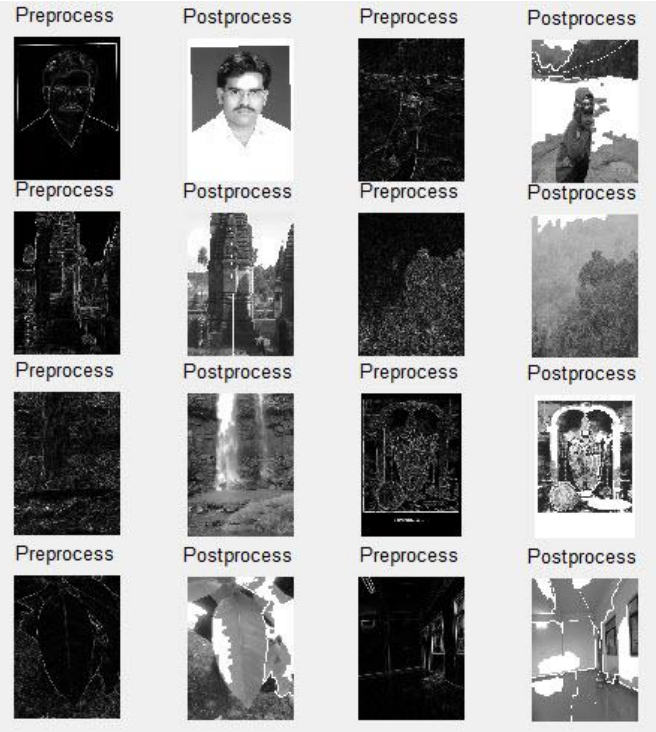

Fig. 4 Result of image segmentation using watershed algorithm

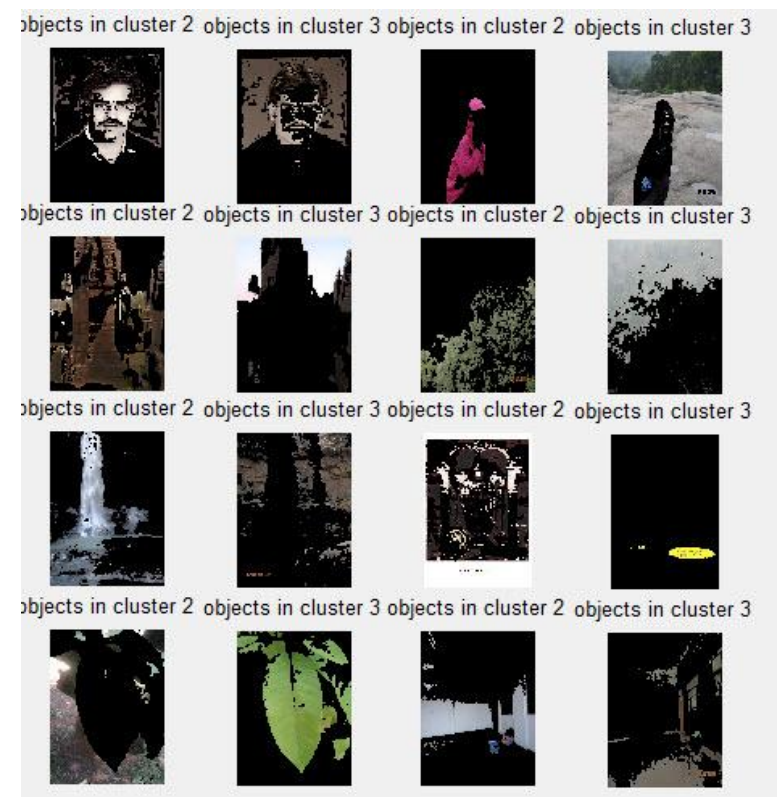

Fig. 5 Result of image segmentation using clustering algorithm

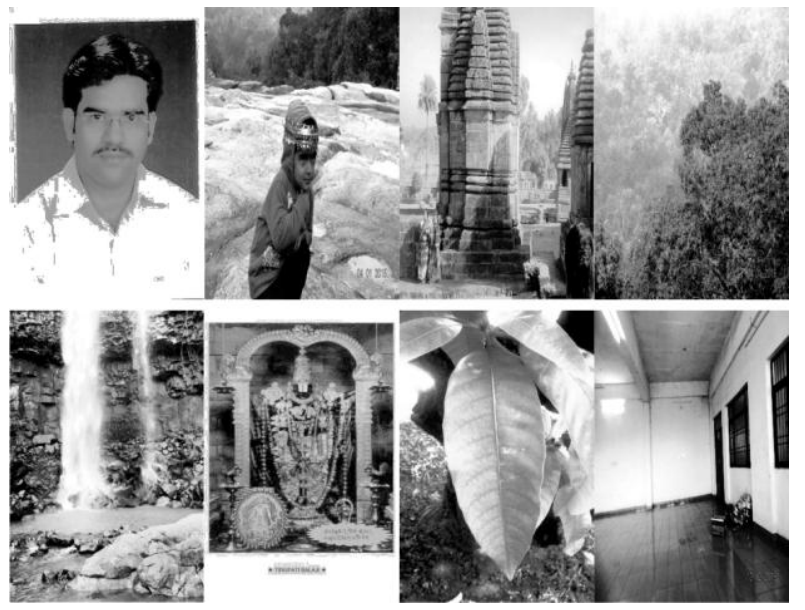

Fig. 6 Result obtained using Simulink based image segmentation 
For further analysis on the image, the quality factors like mse, psnr and ssim is also tested with execution time to produce the requisite result. The table 1 shows the execution time for the eight different images used for the training on image segmentation and table 2 and table 3 shows the performance characteristics for watershed based segmentation and clustering based segmentation respectively.

TABLE I

TIME TAKEN FOR SEGMENTATION (IN SECONDS)

\begin{tabular}{|c|c|c|c|c|c|c|}
\hline \multirow[t]{2}{*}{ Image name } & \multirow[t]{2}{*}{$\begin{array}{l}\text { Size of the } \\
\text { image }\end{array}$} & \multicolumn{2}{|c|}{ Watershed based segmentation } & \multicolumn{2}{|c|}{$\begin{array}{l}\mathrm{C}(\mathrm{K}) \text { - means clustering based } \\
\text { segmentation }\end{array}$} & \multirow{2}{*}{$\begin{array}{l}\text { Simulink } \\
\text { based } \\
\text { segmentation }\end{array}$} \\
\hline & & Pre-process & Post-process & $\mathrm{K}=2$ & $\mathrm{~K}=3$ & \\
\hline Man & $312 \times 418$ & 0.620957 & 2.142138 & 1.593856 & 1.700895 & 0.8 \\
\hline Girl & $4896 \times 3672$ & 0.659163 & 2.298627 & 1.331732 & 1.445781 & 1.0 \\
\hline Temple & $2592 \times 1456$ & 0.679866 & 2.247307 & 1.312882 & 1.418239 & 1.0 \\
\hline Jungle & $4896 \times 3672$ & 0.661337 & 2.241902 & 1.189673 & 1.294347 & 0.8 \\
\hline Waterfall & $3672 \times 4896$ & 0.656080 & 2.267337 & 1.179103 & 1.284712 & 0.8 \\
\hline Balaji & $540 \times 780$ & 0.652699 & 2.188498 & 0.925142 & 1.035629 & 0.8 \\
\hline Leaf & $1536 \times 2560$ & 0.687666 & 2.213982 & 2.027645 & 2.134162 & 0.8 \\
\hline Room & $4896 \times 3672$ & 0.649342 & 2.327629 & 1.181335 & 1.289299 & 1.0 \\
\hline
\end{tabular}

TABLE II

PERFormanCe PARAMETER FOR WATERSHEd BASED SEgmentation

\begin{tabular}{|c|c|c|c|c|c|c|c|}
\hline \multirow[t]{2}{*}{ Image Name } & \multirow[t]{2}{*}{ Image Size } & \multicolumn{6}{|c|}{ Watershed based segmentation } \\
\hline & & $\begin{array}{c}\text { SSIM } \\
\text { (Pre-process) }\end{array}$ & $\begin{array}{c}\text { MSE } \\
\text { (Pre-process) }\end{array}$ & $\begin{array}{c}\text { PSNR } \\
\text { (Pre-process) }\end{array}$ & $\begin{array}{c}\text { SSIM } \\
\text { (Post-process) }\end{array}$ & $\begin{array}{c}\text { MSE } \\
\text { (Post-process) }\end{array}$ & $\begin{array}{c}\text { PSNR } \\
\text { (Post-process) }\end{array}$ \\
\hline Man & $312 \times 418$ & 0.8231 & 74.44 & $29.44 \mathrm{~dB}$ & 0.0207 & 254.75 & $24.10 \mathrm{~dB}$ \\
\hline Girl & $4896 \times 3672$ & 0.5306 & 206.17 & $25.02 \mathrm{~dB}$ & 0.0238 & 252.43 & $24.14 \mathrm{~dB}$ \\
\hline Temple & $2592 \times 1456$ & 0.4965 & 145.62 & $26.53 \mathrm{~dB}$ & 0.0278 & 255.00 & $24.10 \mathrm{~dB}$ \\
\hline Jungle & $4896 \times 3672$ & 0.5163 & 176.78 & $25.69 \mathrm{~dB}$ & 0.0076 & 255.00 & $24.10 \mathrm{~dB}$ \\
\hline Waterfall & $3672 \times 4896$ & 0.3843 & 216.24 & $24.82 \mathrm{~dB}$ & 0.0085 & 254.98 & $24.10 \mathrm{~dB}$ \\
\hline Balaji & $540 \times 780$ & 0.4350 & 173.00 & $25.78 \mathrm{~dB}$ & 0.0182 & 254.99 & $24.10 \mathrm{~dB}$ \\
\hline Leaf & $1536 \times 2560$ & 0.6917 & 143.33 & $26.60 \mathrm{~dB}$ & 0.0303 & 254.94 & $24.10 \mathrm{~dB}$ \\
\hline Room & $4896 \times 3672$ & 0.8421 & 82.68 & $28.99 \mathrm{~dB}$ & 0.0441 & 254.98 & $24.10 \mathrm{~dB}$ \\
\hline
\end{tabular}

TABLE III

PERFormanCe PARAMETER FOR Clustering BASEd SEGMENTATION

\begin{tabular}{cccccccc}
\hline Image & Image Size & \multicolumn{6}{c}{ Clustering based segmentation } \\
\cline { 3 - 8 } Name & & SSIM & MSE & PSNR & SSIM & MSE & PSNR \\
& & $(\mathrm{K}=2)$ & $(\mathrm{K}=2)$ & $(\mathrm{K}=2)$ & $(\mathrm{K}=3)$ & $(\mathrm{K}=3)$ & $(\mathrm{K}=3)$ \\
Man & $312 \times 418$ & 0.4572 & 44.43 & $31.69 \mathrm{~dB}$ & 0.0953 & 66.93 & $29.91 \mathrm{~dB}$ \\
Girl & $4896 \times 3672$ & 0.2422 & 62.29 & $30.22 \mathrm{~dB}$ & 0.0289 & 81.28 & $29.06 \mathrm{~dB}$ \\
Temple & $2592 \times 1456$ & 0.3807 & 47.79 & $29.06 \mathrm{~dB}$ & 0.1795 & 67.85 & $29.06 \mathrm{~dB}$ \\
Jungle & $4896 \times 3672$ & 0.3263 & 49.30 & $29.06 \mathrm{~dB}$ & 0.1596 & 53.58 & $29.06 \mathrm{~dB}$ \\
Waterfall & $3672 \times 4896$ & 0.1914 & 63.71 & $29.06 \mathrm{~dB}$ & 0.2636 & 56.95 & $29.06 \mathrm{~dB}$ \\
Balaji & $540 \times 780$ & 0.4713 & 39.57 & $32.19 \mathrm{~dB}$ & 0.3775 & 47.34 & $31.41 \mathrm{~dB}$ \\
Leaf & $1536 \times 2560$ & 0.3817 & 49.60 & 29.06 & 0.1090 & 70.89 & $29.06 \mathrm{~dB}$ \\
Room & $4896 \times 3672$ & 0.1982 & 65.60 & $29.06 \mathrm{~dB}$ & 0.4470 & 35.04 & $29.06 \mathrm{~dB}$ \\
\hline
\end{tabular}

\section{CONCLUSION}

From the experimental result, it is clear that the watershed segmentation technique takes about three times the time taken by the Simulink design and one $\&$ half times than the time taken by $\mathrm{C}-$ means clustering technique. Although, by testing MSE, PSNR and SSIM quality parameters of the three techniques, it is found that the Simulink design is prefer only when the speed of execution is matters and not the image quality, watershed segmentation is prefer for the quality but it will take more time and the fuzzy $\mathrm{C}$ - means clustering is gives the moderate quality of image compared to watershed segmentation and also took less time compared to watershed segmentation technique. To improve the quality of the image using fuzzy $\mathrm{c}-$ means clustering it is propose that prior to apply $\mathrm{C}$ - means of clustering the images may be first process (pre-process as in watershed segmentation) using genetic algorithm

\section{REFERENCES}

[1] Jang J. S. R., Sun C. T. and Mizutani E., "Neuro - Fuzzy and Soft Computing", Eastern Economy Edition Prentice Hall of India, 2014.

[2] Feng Zhao, Hanqiang Liu and Jiulun Fan, "A Multiobjective Spatial fuzzy clustering algorithm for image segmentation”, Elsevier Journal of Applied Soft Computing, Volume 30, May 2015, Pages 48 - 57. http://dx.doi.org/10.1016/j.asoc.2015.01.039

[3] Bhagwat Manisha, Krishna R. K. \& Pise Vivek, "Simplified Watershed Transformation", International Journal of Computer Science and Communication, Vol.1, No. 1. pp. 175-177, 2010

[4] Manisha Kaushal, "A Review of Soft Computing Approaches for Edge Detection", International Journal of Emerging Research in Management \&Technology, Volume-2, Issue-11, November 2013.

[5] Sarker Md. Shakowat Zaman, Haw Tan Wooi and Logeswaran Rajasvaran, "Morphological based technique for image segmentation", International Journal of Information Technology, Vol. 14, No. 1.

[6] Piedad Brox, Iluminada Baturone, Santiago Sanchez-Solano, and Julio Gutierrez-Rios, "Edge-adaptive Spatial Video De-interlacing Algorithms Based on Fuzzy Logic", IEEE Transactions on Consumer Electronics, Volume 60, No. 3, August 2014. http://dx.doi.org/10.1109/TCE.2014.6937321 
[7] Jose A. Piedra-Fernandez, Gloria Ortega, James Z. Wang, and Manuel Cantón-Garbın, "Fuzzy Content-Based Image Retrieval for Oceanic Remote Sensing", IEEE Transactions On Geoscience And Remote Sensing, Volume 52, No. 9, September 2014. http://dx.doi.org/10.1109/TGRS.2013.2288732

[8] Long Chen, C. L. Philip Chen, and Mingzhu Lu, "A Multiple-Kernel Fuzzy C-Means Algorithm for Image Segmentation", IEEE Transactions On Systems, Man, And Cybernetics, 2012.

[9] Siti Noraini Sulaiman and Nor Ashidi Mat Isa, "Adaptive Fuzzy-Kmeans Clustering Algorithm for Image Segmentation", IEEE Transactions on Consumer Electronics, Volume 56, No. 4, November 2010. http://dx.doi.org/10.1109/TCE.2010.5681154

[10] Wang, Baoping, Fang, Yang, Sun and Chao, "Image segmentation algorithm based on high dimension fuzzy character and restrained clustering network", IEEE Transactions on System Engineering and Electronics, Volume 25, No. 2, July 2014

Nilesh B. Bahadure is currently an Associate Professor and Dean Research Development at Bhilai Institute of Technology Raipur. He obtained his Bachelor of Engineering from Nagpur University. He received his Master of Engineering degree in Digital Electronics from Amravati University. He had published one book on Advanced Microprocessor published by PHI Learning Pvt. Limited, and reviewed one book on Basic Electrical Engineering, Published by Pearson Education Pvt. Limited. He also had two papers in International Journal, six in National Journal. He is a Life Member of various institutions like ISTE, IETE, IE (India), SESI, ISRS, and ISCA.

Arun Kumar Ray is currently Professor \& Dean School of Electronics at KIIT University Bhubaneswar. He is a Life member of various institutions like ISTE, IETE, IE (India) and active member of international professional bodies like IEEE, MIET. He is also serve as a Member in the Editorial board of some reputed international journals.

Harpal Thethi is currently Professor in Electronics Engineering \& Dean Industry Institute Interface at Rungta Group of Institutions Bhilai - Raipur. $\mathrm{He}$ received his B.Tech from BIET Bhadrak, M.Tech from NIT Rourkela and $\mathrm{PhD}$ in Electronics Engineering from KIIT University Bhubaneswar. He is a Life Member of various institutions like ISTE, ISCA. He is also an active member of international professional bodies like IEEE, Institution of Engineering and Technology. 